University of Louisville

ThinkIR: The University of Louisville's Institutional Repository

Electronic Theses and Dissertations

$12-2010$

\title{
Effects of short-term, high-force resistance training on high- intensity exercise capacity.
}

Patrick Abi Nader

University of Louisville

Follow this and additional works at: https://ir.library.louisville.edu/etd

Part of the Exercise Science Commons

\section{Recommended Citation}

Abi Nader, Patrick, "Effects of short-term, high-force resistance training on high-intensity exercise capacity." (2010). Electronic Theses and Dissertations. Paper 9.

https://doi.org/10.18297/etd/9

This Master's Thesis is brought to you for free and open access by ThinkIR: The University of Louisville's Institutional Repository. It has been accepted for inclusion in Electronic Theses and Dissertations by an authorized administrator of ThinkIR: The University of Louisville's Institutional Repository. This title appears here courtesy of the author, who has retained all other copyrights. For more information, please contact thinkir@louisville.edu. 


\title{
EFFECTS OF SHORT-TERM, HIGH-FORCE RESISTANCE TRAINING ON HIGH- INTENSITY EXERCISE CAPACITY
}

\author{
By \\ Patrick Abi Nader \\ B.A., and T.D., University of Balamund, 2008
}

A Thesis

Submitted to the Faculty of the

College of Education and Human Development of the University of Louisville

in Partial fulfillment of the Requirements

for the Degree of

Master of Sciences

Department of Exercise Physiology

University of Louisville

Louisville, Kentucky

December 2010 
Copyright 2010 by Patrick Abi Nader

All rights reserved 



\section{EFFECTS OF SHORT-TERM, HIGH-FORCE RESISTANCE TRAINING ON HIGH INTENSITY EXERCISE CAPACITY}

\section{By}

Patrick Abi Nader

B.A., and T.D., University of Balamand, 2010

A Thesis approved on

November 23, 2010

By the following Thesis Committee: 


\begin{abstract}
EFFECTS OF SHORT-TERM, HIGH-FORCE RESISTANCE TRAINING ON HIGH INTENSITY EXERCISE CAPACITY
\end{abstract}

Patrick Abi Nader

November 23, 2010

The purpose of this study was to assess the effects of short-term high-intensity resistance training on time to exhaustion at maximal aerobic output. It was hypothesized that 2 weeks of training will induce improvements in performance at maximal aerobic output. Eighteen subjects participated in this study. Subjects were assigned to a control $(n=8)$ or resistance training $(n=10)$ groups. The resistance training group participated in 5 sessions of strength training over a period of 2 weeks on the leg press device. Both groups participated in pre and post intervention testing. After the intervention strength in the training group significantly increased $(\mathrm{p}=.00)$. Time to fatigue at maximal aerobic exercise did not significantly change between groups. There was a time improvement of $38.96 \%$ in the women of the training group, whereas men decreased their times to fatigue. The main finding of this study was that men and women reacted differently to short-term strength training, and to time to fatigue at maximal aerobic output. Clearly there is a need for more research this study cannot conclude which factor is a predicator of time to fatigue. 


\section{TABLE OF CONTENTS}

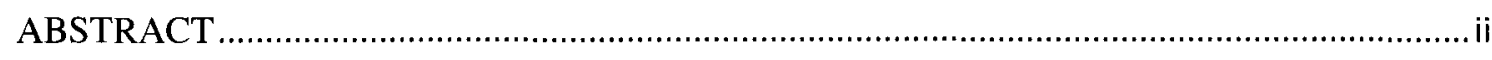

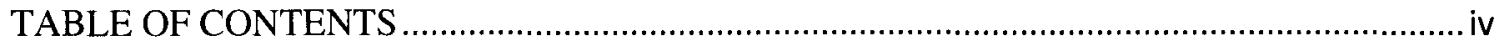

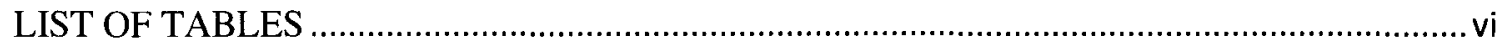

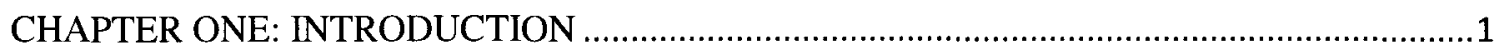

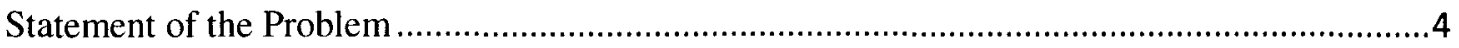

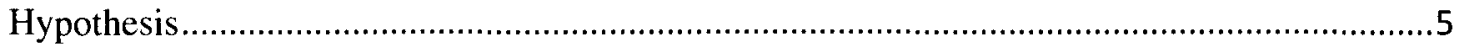

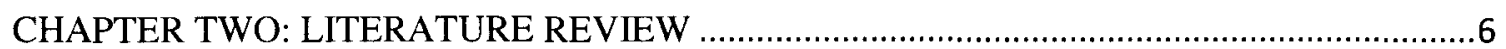

Effects of strength training on muscle physiology: ......................................................

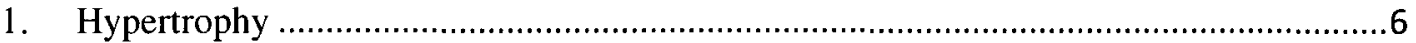

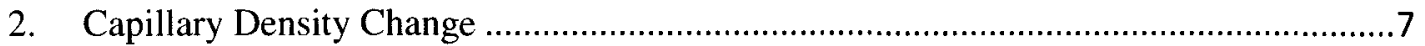

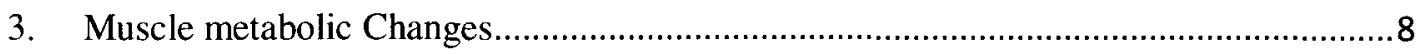

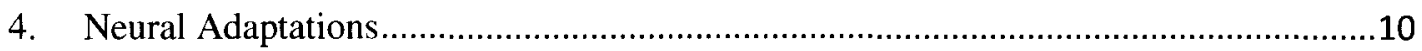

5. Strength Training and Endurance Performance ….................................................12

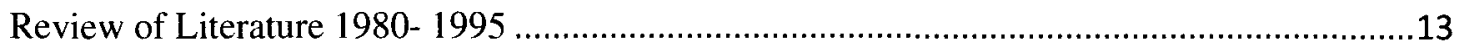

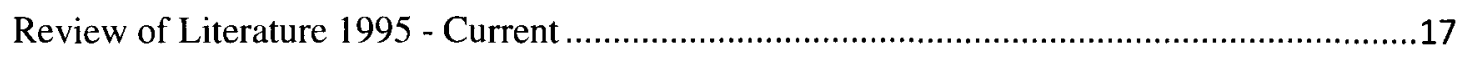

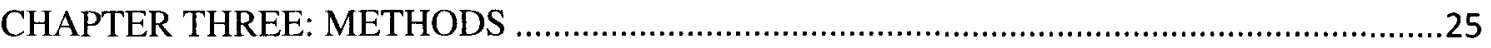

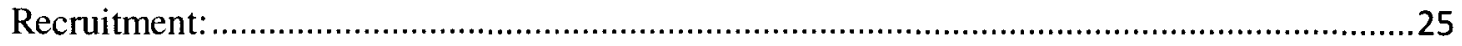

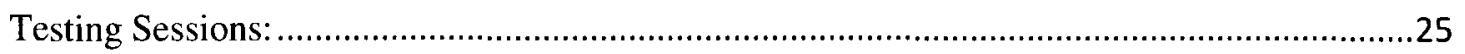

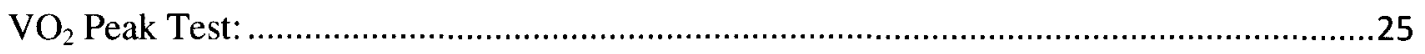

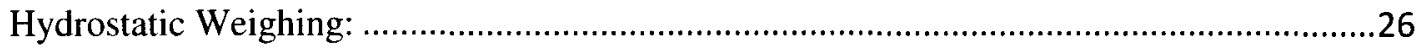

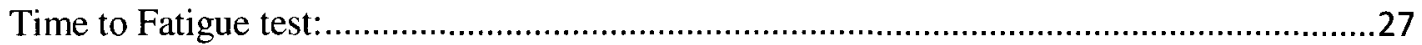

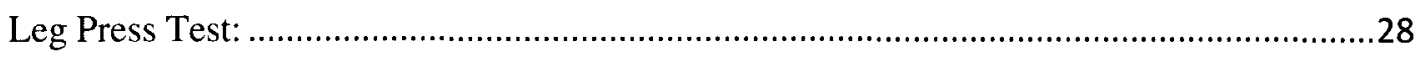

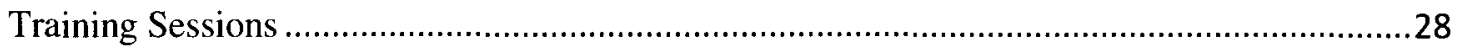

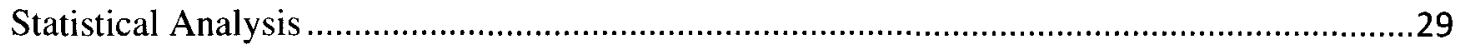

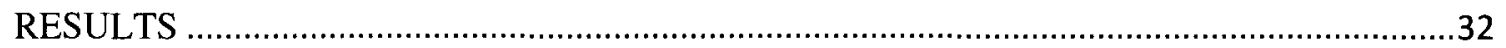

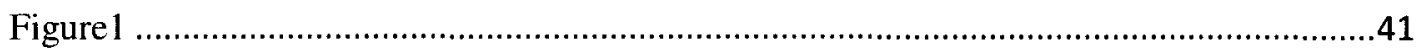

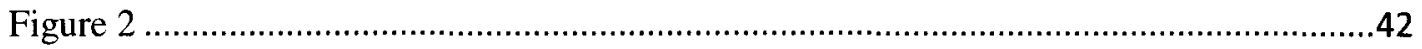




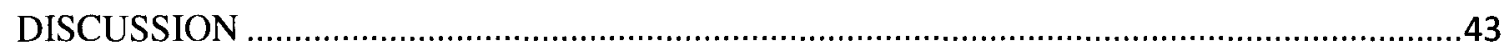

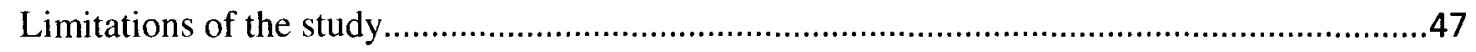

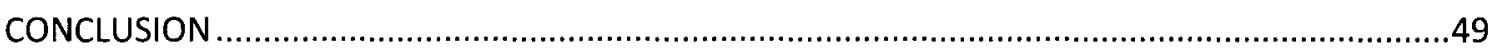

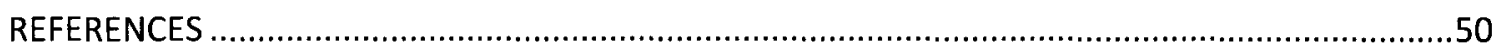

CURICULUM VITAE 


\section{LIST OF TABLES}

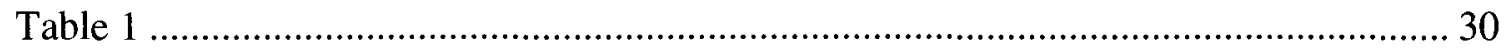

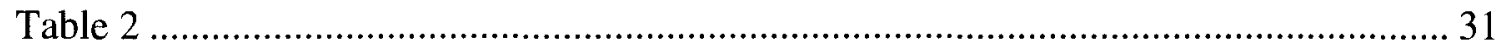

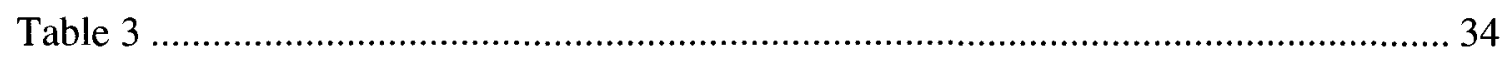

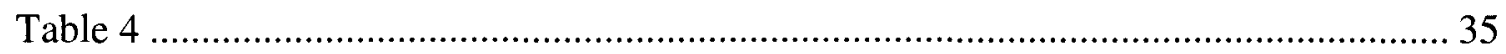

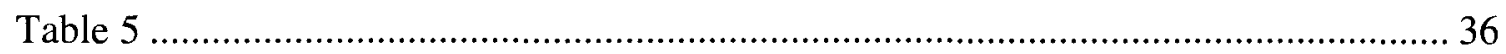

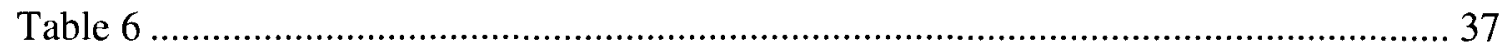

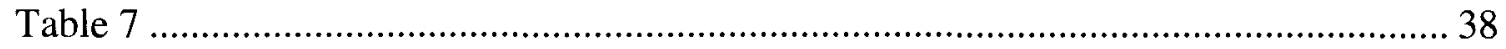

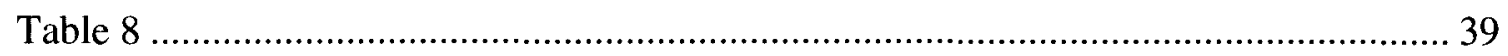

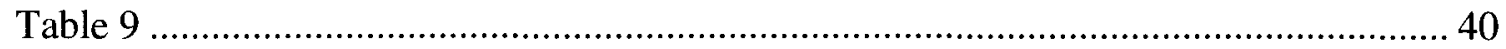




\section{CHAPTER ONE: INTRODUCTION}

High level physiological performance occurs as a result of a combination of intense and intelligent training, in addition to inherent talent which is genetically determined. Some individuals have the genetic ability to perform better than others. However, the probability of one achieving their genetic potential is significantly increased with well planned individual training sessions and yearly training plans. However, whether genetically gifted or not, all individuals must engage in exercise in order to improve and maintain physical ability. The study presented in this paper will examine short term high resistance strength training as a means to improve performance.

One key measure of high intensity exercise and aerobic capacity is $\mathrm{VO}_{2} \mathrm{max}$--the maximum volume of oxygen uptake-which can be used to assess whether energy provision is occurring aerobically or anaerobically. Both the aerobic and the anaerobic pathways work on sustaining effort at $100 \%$ of $\mathrm{VO}_{2} \max$ (Bangsbo et al. 1990). The duration one can sustain a given exercise intensity is termed "Time to Fatigue". Time to fatigue at $100 \% \mathrm{VO}_{2}$ peak is commonly used to measure high intensity performance and aerobic capacity and usually lasts 3 to 8 minutes (Ball et al. 1996; Hickson et al. 1988; Jung and Jung 2003; Lambert et al. 1993; Renoux et al. 2000).

Two main substrates present in the body -fat and carbohydrates- provide ATP production during exercise. Depending on the intensity and duration of exercise, the body will use one substrate to provide energy more than the other 
(Brooks and Mercier 1994; Coyle 1995). Aerobic exercise utilizes both substrates while anaerobic exercise utilizes only carbohydrates. The greater the intensity of exercise the more carbohydrates are utilized for ATP production (Brooks and Mercier 1994). Bangsbo et al. reported that a one legged exercise resulting in fatigue at approximately $3 \mathrm{~min}$ has approximately $45 \%$ of anaerobic contribution and $55 \%$ of aerobic contribution (1990).

The intensity and the duration of the exercise determine substrate utilization. High intensity exercise is difficult to maintain whereas lower intensity is easier to maintain. In the former case energy is provided mainly by the anaerobic system, in the latter case aerobic system has a greater contribution.

The study of Lambert et al. (in review) provided pilot work for the current study. The researchers found that fat free mass (and primarily muscle mass) is a substantial predictor of time to fatigue at $100 \%$ of $\mathrm{VO}_{2}$ max during cycle exercise. Typically, exercising at $100 \%$ of $\mathrm{VO}_{2}$ max is seen in several different sports that include: $1500 \mathrm{~m}$ and $800 \mathrm{~m}$ middle distance running; $400 \mathrm{~m}$ and $200 \mathrm{~m}$ swimming; $200 \mathrm{~m}$ to $2000 \mathrm{~m}$ rowing (Hill et al. 2003; Jung and Jung 2003; Wakayoshi et al. 1993). Hanon et al, 2008 studied $\mathrm{O}_{2}$ consumption in a $1500 \mathrm{~m}$ run, and found that from the onset of exercise runners performed at maximal $\mathrm{VO}_{2}$ (Hanon et al. 2008). It follows then that adding muscle mass and/or strength may be a way to improve time to fatigue at this intensity. Therefore increased muscle mass could improve 
performance at onset of high intensity exercise. Several researchers evaluated the best method to improve time to fatigue at $100 \%$ of $\mathrm{VO}_{2} \max$. In an effort to improve endurance performance, Hickson et al, 1980 conducted a study to determine the effects of heavy strength training on high intensity aerobic exercise. Nine subjects participated in that study and after 10 weeks of heavy resistance training 5 times a week, subjects' time to exhaustion on a cycle ergometer improved $47 \%$ and $12 \%$ on a treadmill. This study showed improvements in exhaustion time without any change in $\mathrm{VO}_{2}$ max measurements (Hickson et al. 1980). This classic study will be further elaborated on later in the review of literature.

Other researchers attempted the use of strength training to improve time to fatigue at maximal aerobic effort; some noted significant improvements (Hickson et al. 1988; Hickson et al. 1980; Hoff et al. 2002; Storen et al. 2008) while others did not (Kelly et al. 2008). All of the afore mentioned studies strength-trained the participants for more than 7 weeks, whereas the current study will focus on a two-week training period in order to maximize neural adaptations and minimize muscle mass development.

Many factors affect physical performance including gender. Within the same gender, performance and capacities differ, as well as between genders. Notably, women have a greater capacity of oxidizing fat in long duration exercise (Tarnopolsky and Tarnopolsky 2008), but the genders also differ in the way they perform the anaerobic type of exercise (e.g. sprinting, see (Simoneau and Bouchard 1989). A study examining difference on time to fatigue between genders at $100 \%$ of $\mathrm{VO}_{2}$ peak (Lambert et al, 2009 In review) found that men lasted $\sim 48 \%$ longer than women. This finding was explained mainly by the difference in fat free mass between genders. 
Strength training adaptations include morphological, neurological and physiological adaptations (Andersen and Aagaard; Folland et al. 2007; Hakkinen et al. 1996; Hoff et al. 2002; Leveritt et al. 1999; Tesch 1988; Tesch et al. 1987). The neuromuscular adaptation is best explained by learning a skill and improving the coordination of the movement. Lambert et al, 2005 in a review article discussed the adaptations to long duration and anaerobic exercise in the elderly. Lambert et al, states that the neurologic factors that modulate muscle induced force production are motor unit recruitment, and the rate of motor unit firing. This indicates activating unnecessary agonistic muscles, the body activates the necessary muscles to induce a movement. This finding implies better fiber recruitment when performing tasks. Neuromuscular adaptations are the main improvements of strength after 2 weeks of training (Folland et al. 2007).

The study presented here is designed to assess the effects of short-term high intensity exercise ( 2 weeks of strength training) on time to fatigue at $100 \%$ of $\mathrm{VO}_{2}$ peak.

\section{Statement of the Problem}

Research has shown many benefits of strength training including improvement in muscle hypertrophy, increased lactate threshold, increased glycogen reservoir, and injury prevention. Yet studies have also indicated negative effects including a relative decrease in the number of capillaries, decreased mitochondrial number, and decreased endurance performance markers. In order to maximize performance, researchers have sought methods to obtain strength training benefits without losing endurance performance capacities. Recent studies have provided some evidence that strength training produces an increased capacity to perform high-intensity aerobic exercise. 
This improvement in performance of high-intensity aerobic exercise has been explained by a number of theories. Studies have postulated that the change was due to increased lactate threshold, improved exercise economy, and neurological adaptations.

A pilot study attributed differences between genders in time to fatigue to fat free mass which could indicate that in short term high intensity training, performance may be due to muscle mass. In an attempt to check the validity of such a theory the current study examined the effects of short term high intensity program on maximal aerobic performance.

The body of knowledge has already established that the first 2 to 3 weeks of strength training are only neural adaptations (i.e. Learning a specific activation and motor unit recruitment) (Folland et al. 2007).

The current research project will study the effects of high intensity training on time to fatigue between genders, in a period of time less than that required for the development of muscle hypertrophy maximizing neural impact- 2 weeks- The study will examine whether a group of healthy active young adults will improve on time to fatigue at $100 \%$ of $\mathrm{VO}_{2}$ peak after participating in 6 high intensity strength training sessions compared to a control group that will participate in the pre and post testing sessions.

\section{Hypothesis}

It was hypothesized that if short-term resistance training improves time to fatigue at $100 \%$ of $\mathrm{VO}_{2}$ peak neuromuscular adaptations would be responsible for the improved performance at this intensity. In case performance does not change fat free mass would be a better predictor of performance at high intensity aerobic exercise. 


\section{CHAPTER TWO: LITERATURE REVIEW}

\section{Effects of strength training on muscle physiology:}

Strength training is best described as a "training that in an efficient manner induces a measurable increase in muscle strength or/and hypertrophy" (Folland et al. 2007).The existent body of knowledge established the physiological changes that occur in the human body after undergoing a strength training program. Those changes are outlined in the following sections.

\section{Hypertrophy}

Hypertrophy-the expansion of muscle mass resulting from strength training - is the most commonly known and noticeable effect of strength training, is the result of overloading (Tesch and Larsson 1982). Strength training creates a disturbance in the balance of protein synthesis and degradation. This disturbance will either lead to hypertrophy or atrophy of the muscle fibers. Two main processes will lead to hypertrophy and are measurable after 4 to 6 weeks of intensive resistance training (Andersen and Aagaard). The first is the increase of muscle protein synthesis and the second is the proliferation of myogenic satellite cells (Folland et al. 2007). Both processes start immediately after the first session of strength training (i.e. as soon as 4 hrs after strength training), with protein synthesis detectable in exercising muscles (Fry and Fry 2004). Protein synthesis is more pronounced in the first few weeks. Most hypertrophy effects depend on protein synthesis. After a certain period of time when the skeletal muscle cells 
can no longer accommodate the enlarged cytoplasm, the satellite cells will commence the creation of new myonuclei to help with cellular hypertrophy (Andersen and Aagaard).This mechanism of satellite cell proliferation coupled with protein synthesis during strength training explains the actual increased muscle mass during strength training exercise activity.

\section{Capillary Density Change}

Tesch et al, 1984 compared muscle capillary supply in "weight and power lifters" (i.e. typical bodybuilders) with "endurance athletes" (e.g. road racing cyclists and runners) and "non-endurance athletes" (combat airman from the Swedish Air force). Weight lifters had the same number of capillaries as the non-endurance athletes. But compared to muscle size and surface, non-endurance athletes had more muscle capillaries per area of the muscle compared to the weight and power lifters. Endurance athletes had more capillaries than any of the groups (Tesch et al. 1984). This finding was particularly interesting because the researchers expected that the weight and power lifters would actually have developed more capillaries than any of the other groups. Instead, these findings point to the fact that as muscle mass increases, the relative number of capillaries decreases due to the absence of creation of new capillaries. 
Controversy remains on whether strength training results in capillary growth in type II fiber muscles. Jensen et al, 2004 examined two different training protocols 1) using $150 \%$ of one repetition maximum (1RM) and 2) using $90 \%$ of $1 \mathrm{RM}$ to determine if either would induce different capillary proliferation. They found at week 4 of training in both groups capillary number increased, but at week 7 of training capillary supply did not improve further. The investigator of this study proposed that since strength training doesn't require a highly oxygenated blood supply, then the initial increase in capillary proliferation was due to the introduction of weight training activities. Following this initial period no further increase was noted as the muscle fibers did not need an increased supply of oxygenated blood (Jensen et al. 2004). This finding is important to support that performance improvements in strength are not the result of capillary growth around exercising muscle.

\section{Muscle metabolic Changes}

Metabolic responses to strength training include increased lactate threshold, mitochondrial changes, presence of glycogen in muscle, and unchanged glycolytic enzyme activity.

During strength training, energy provided and muscles are activated depending on the effort. The heavier the load the more fast-twitch fibers are recruited, and energy turn over will be provided through anaerobic (ATP-CP breakdown and anaerobic glycolysis) pathways. Tesch et al, (1986) found that strength type exercises (front squats, back squats, leg press and knee extension) induced a significant decrease in muscle glycogen 
and a high concentration of muscle lactate in strength trained athletes. The anaerobic glycolysis can maintain energy provision up to $2 \mathrm{~min}$ of intense exercise. An indicator for the extensive mobilization of the anaerobic pathway is Lactate Threshold (i.e. when lactic acid production exceeds lactic acid removal). The presence of lactate in the blood stream induces muscle fatigue (Sesbo et al.). Indeed lactate threshold can be improved by strength training exercise in untrained individuals (Marcinik et al. 1991). Lactate threshold does not increase in trained subjects (Jung and Jung 2003). Furthermore, strength training does not affect endurance performance in this population (Jung and Jung 2003). Lactate threshold is an important aspect of muscle adaptations to strength training. Exercising at the same intensity before and after strength training will cause energy provision from a different metabolic pathway, decreasing rate of lactate production enabling the exercising muscle with an extra margin for performance. Strength training can as well elevate the tolerance for acid environment. In fact strength training induces production of lactic acid. The exercising muscle will build up a tolerance for working in such environment increasing the lactate threshold. Marcinik et al, 1991 noticed an increased lactate threshold after 12 weeks of strength training exercise in healthy untrained males.

Possible metabolic changes induced by strength training include decreased mitochondrial density, decreased enzymatic adaptations and increased glycogen availability in the exercising muscle. Strength training uses the energy provided by the anaerobic glycolytic pathway (Tesch et al. 1986). Therefore strength training has the capacity to deplete glycogen reservoir. When depleted, glycogen is found to be restored in greater amounts due to strength training (Putman et al. 1998). Strength training 
increases glycogen availability in the specific exercising muscle. Prolonged strength training periods induces muscle hypertrophy. This increase in muscle mass is accompanied with a decrease in capillary density relative to area of the muscle, and is also accompanied with a decrease in mitochondrial and enzymatic activity (Tesch 1988;

Tesch et al. 1987). Tesch et al, (1987) studied 21 physically active men over a period of 9 months. In the first 6 months, subjects were assigned to either an explosive or heavy intensity strength training protocol. The last 3 months of the period was a detraining period. Muscle biopsies were obtained from the vastus lateralis and were assessed for the presence of hexokinase, myofibrillar ATPase, citrate synthase, phosphofructokinase, lactate dehydrogenase, myokinase and creatine kinase. The results of the study showed decreased enzyme activity for all of the enzymes except lactate dehydrogenase. It was concluded that hypertrophy of the muscle is also accompanied with decreased enzyme activity during glycolysis.

\section{Neural Adaptations}

Hardman et al, (1984) tested the effects of one leg training on $\mathrm{VO}_{2}$ max and long duration performance in men. Their findings reported improvement in both the untrained and trained limb, at $150 \%$ and $340 \%$ respectively, in endurance performance. This finding was thought to be an improvement in muscle metabolism for both the trained and untrained limb. However, continued research did not support this theory. Pre- and posttesting following a six week endurance training protocol showed improvement in endurance performance in both limbs, but no changes in concentration of muscle 
metabolites in the untrained limb (Hardman et al. 1987). A follow-up study by Hardman et al, 1987 concluded that improvement in both limbs (trained and untrained) was due to neural adaptations.

Further research has explored the relationship between neural muscle adaptation and strength training (Bemben and Murphy 2001; Del Balso et al. 2007; Folland et al. 2007; Hakkinen et al. 1996; Judge et al. 2003). These research projects indicated that improvement in strength first occur by improved neuromuscular activation. Learning a specific activation and motor unit recruitment pattern is commonly called neuromuscular adaptation. When a new physical task is being taught the brain activates all the muscles required to perform the task and the muscles not required. Over time the brain creates a pattern that will increase efficiency of the muscle activated with training. Only specific motor units are activated for sufficient required effort. Strength training induces large motor unit recruitment and to accomplish increase force of contraction. Familiarization trials increase strength performance by improvement in neuromuscular recruitment.

The current study subject of this literature review proposed the implementation of a short term high intensity exercise training program. Current research attributes improvements in strength in short term strength training to neurologic adaptations. A study of short term resistance training ( 2 weeks) in young and old women (young 20 years old, and old 58 years old) induced strength improvement in 1RM of trained and untrained elbow flexors of $28 \%$ and $12-15 \%$ respectively. A cross sectional examination of muscle area indicated no change and the authors noted a decrease in efficiency of electrical activity. Thus, the improvements in strength were attributed to neural adaptations (Bemben and Murphy 2001). 
To summarize, studies have failed to show that improvement in muscle strength after short term strength training is accompanied with 1) hypertrophy of muscle fiber, 2) changes in muscle metabolic capacities, and 3) changes in muscle capillarization. Therefore, several authors have concluded that the improvement is due to neuromuscular adaptations that include augmentation of the rate of activation and increased motor unit recruitment (Del Balso et al. 2007; Judge et al. 2003; Lambert et al. 2005). Therefore neural muscle adaptations that occur after a short term ( 2 weeks) high intensity heavy strength training protocol are the most important effect examined by the current study.

\section{Strength Training and Endurance Performance}

Strength training and endurance performance are two distinctly different types of training programs. Strength training increases muscle mass, decreases relative number of capillaries compared to fiber muscle size, and causes the decrease of endurance performance markers (e.g. number of mitochondria). In a way strength training is antagonistic to endurance performance. Aerobic performance requires elevated blood flow, high enzyme activity, and many other markers that extended periods of strength training may prevent from occurring. Many studies have evaluated the use of strength training to attempt to cause improvement in endurance performance, and found either positive or no negative outcomes for this type of exercise on endurance activity (Hickson et al. 1988; Hickson et al. 1980; Hoff et al. 2002; Kelly et al. 2008; Marcinik et al. 1991; Ronnestad et al. ; Storen et al. 2008). 
One notable example of an activity that can be enhanced through strength training exercise and can directly affect endurance performance is running economy (improvement in running efficiency due to improvements in strength). Running economy is composed of two variables: running velocity and required oxygen consumption. The first outcome of strength training is increased muscle strength. After the strength training protocol, work will be performed at a lower $\mathrm{VO}_{2} \max$ if maintaining the same speed as used in the pre test. Because of the improvement in strength, the runner can maintain the same pace using less effort. The inverse is also true. Post training, for the runner to reach the same $\mathrm{VO}_{2} \mathrm{max}$, he/she will have to run at a faster pace. Again improvements in strength caused this change of speed (i.e. the runner must run faster to require the same amount of energy production since the effort at the prior speed was now easier)(Jung and Jung 2003). In conclusion muscle fibers following strength training are able to produce more absolute force (Jung and Jung 2003). Therefore muscles would work at a relative lower percentage of maximum strength during endurance exercise post-training as compared with pre-training values.(Jung and Jung 2003)

\section{Review of Literature 1980- 1995}

This section will discuss the first evidence that was provided supporting the hypothesis that strength training is beneficial for endurance performance and does not alter the metabolic attributes of long duration exercise.

In the late seventies Hickson et al., 1980 conducted a study at the University of Illinois. The main purpose was to look at the effects of strength training on aerobic power and short-term endurance. Their study was developed to determine if strenuous heavy resistance training has the potential of increasing work capacity and $\mathrm{VO}_{2}$ max. They 
recruited 9 healthy men (age range 18-27 years old). Who engaged in strength training five times per week over a period of 10 weeks. Training consisted of lower body exercises, and exercises were performed in either three sets of five repetitions, or five sets of five repetitions. The subjects started first with eighty percent of their IRM, and then they were asked to perform the sets at a maximal weight. Strength measurements were assessed by 1RM. The main outcome of the study was measuring time to exhaustion at $100 \% \mathrm{VO}_{2}$ max. The measurement was done on both a stationary bike and a treadmill. Blood samples were obtained: at rest, after the treadmill and bicycle test, and before and after the training. Body fat percentage was assessed and thigh sizes were measured pre and post training. After ten weeks of training, researchers observed 38, 42, and 50\% improvements respectively in the $1 \mathrm{RM}$ of the parallel squats, knee flexion and knee extension. Thigh girth increased, body fat decreased and body weight increased. The $\mathrm{VO}_{2}$ max results did not differ significantly from the pre to post test. On the other hand time to fatigue improved $47 \%$ on the bike test and $12 \%$ on the treadmill. Blood lactate was approximately the same after training. The major finding of this study was that heavy resistance training is capable of increasing short-term endurance performance. This study was performed on healthy individuals, who were not trained athletes. These improvements in short-term endurance performance as a result of strength training are important to athletic performance. Researchers were interested in studying different aspects of the phenomenon to understand how it was possible that resistance training would enhance time to exhaustion which in comparison is more an aerobic type of exercise. 
In a follow up study Hickson et al, 1988 investigated the effects of combined strength and endurance training on endurance performance. The subjects recruited were trained cyclist and runners (men $n=6$, women $n=2$ ). The subjects performed constant endurance training during a period of 10 weeks of 3 days a week of strength training. Strength training exercises aimed at improving leg strength consisted of parallel squats (5 sets of 5 repetitions), knee extensions ( 3 sets of 5 repetitions), knee flexions ( 3 sets of 5 repetitions), and toe raises (3 sets of 25 repetitions). Participants underwent pre and post testing which included measurements of $\mathrm{VO}_{2}$ max, strength (1RM of; parallel squat, knee extension and knee flexion), long-term endurance (time to exhaustion at 80 to $85 \%$ of $\mathrm{VO}_{2}$ max on a cycle ergometer, and $10 \mathrm{~km}$ indoor running times), short term endurance (time to exhaustion at maximal work rate for both running and cycling), body fat analysis (skin fold), and muscle biopsies (taken from the vastus lateralis to measure fiber type composition and citrate synthase activity). Strength improved an average of $30 \%$, body composition (i.e. fiber type and citrate synthase) and $\mathrm{VO}_{2}$ max remained unchanged, short-term endurance increased $11 \%$ and $13 \%$ respectively in cycling and running performance, long-term endurance increased $20 \%$ in cycling but was not significantly different during the $10 \mathrm{~km}$ running test. The main finding of this study was that strength training has the potential to improve short-term high intensity endurance performance. The adaptations to strength training that were observed in this study were attributed to neuromuscular factors (i.e. learning a specific activation and motor unit recruitment), since muscle size and citrate synthase activity remained the same. This article is of importance because it was the first one to discuss that improvements on time to fatigue 
from strength training can be related to neuromuscular adaptations and not related to muscle hypertrophy or metabolic changes in the muscle cells.

Marcinik et al, 1991 sought to build on the work of Hickson et al $(1980,1988)$. The project analyzed the effects of strength training on lactate threshold. Eighteen healthy males (ages 25-34) participated in the study. Ten of them were randomly assigned to a training group and the remaining eight served as the control group. The training group trained for 12 weeks, 3 days per week. Training sessions consisted of 3 sets of 10 circuit training exercises. The exercises included: bench press (8-12 RM), hip flexor (15-20 RM), knee extension (15-20 RM), knee flexion (15-20 RM), push-up (15$20 \mathrm{RM})$, leg press (15-20 RM), lat-pulldown (8-12 RM), arm curl (8-12 RM), parallel squat (15-20 RM), and bent knee sit-up (15-20 RM). There was no significant difference in body weight, fat free mass or body fat percentage after the 12 weeks of strength training. The training protocol increased $1 \mathrm{RM}$ values. $\mathrm{VO}_{2} \max$ and cycle peak $\mathrm{VO}_{2}$ remained unchanged despite that the main finding of this study was that strength training induced improvements on time to exhaustion at $75 \%$ of $\mathrm{VO}_{2}$ peak and that lactate threshold increased. The reduction of blood lactate after the strength training program can indicate that different substrates were recruited to maintain required energy levels during different intensities of exercises. The fuel selection changed as a result of the training protocol (i.e. subjects from the training group improved in muscle strength). So the provision of energy for one specific performance (using the same speed before and after the training duration) will require the use of different pathways to produce the same amount of energy (Marcinik et al. 1991). 
To conclude this section three different studies (Hickson et al. 1988; Hickson et al. 1980; Marcinik et al. 1991)found that time to fatigue (i.e. at maximal effort or $75 \%$ of maximal effort) was improved as a result of strength training. Each study utilized a strength training protocol 10 to 12 weeks long, and did not find any change in muscle size or body fat composition. The reasons for the improvements in time to fatigue were not clearly understood. The next section will discuss more recent articles that attempted to clarify the underlying mechanism.

\section{Review of Literature 1995 - Current}

During the years prior to the "running boom" (1972), when running started gaining popularity), and for some years after, it was uncommon for long distance runners to engage in resistance training. Traditional high force, low repetition strength training has been shown to increase muscle mass and improve motor unit recruitment but also to decrease relative capillary density and mitochondrial volume (Tesch et al. 1987). The nature and the specificity of the training is very important. Tesch et al 1988 reported that body builders (i.e. people who strength train with a high repetition program) displayed a small increase in capillaries per muscle fiber. In contrast, strength and power lifters had no increase. Analyzing this report explains that the way muscle is trained highly affects the way it will perform. This justification is why endurance athletes did not implement any kind of strength training into their regular workouts - because strength training would not result in improved endurance performance.

However, research has shown that strength training can improve time to fatigue during predominately aerobic exercise without altering muscle mass or muscle composition (Hickson et al. 1988; Hickson et al. 1980; Kelly et al. 2008; Marcinik et al. 
1991; Storen et al. 2008). Conversely, endurance training enhances cardio-respiratory function yet no changes or decreases in muscle fibers size are noticeable (McCarthy et al. 2002). Some cases show increase in muscle size following an aerobic training protocol (Harber et al, 2009.

A study by Hoff et al, 2002 details the effects of strength training on endurance performance. This study explored the effects of maximal strength training on aerobic endurance performance. A total of 19 professional cross country skiers were recruited for this study and were randomly assigned to a control group $(n=10)$ or a training group $(n=9)$. The intervention group trained 3 times a week for 8 weeks using a cable pulley to imitate the double polling technique in cross country skiing. Each session consisted of 3 sets of 6 repetitions using $85 \%$ of maximum workload. Results of the study found that IRM significantly increased $9.9 \%$, peak force at $80 \%$ of $1 \mathrm{RM}$ significantly changed by $34 \%$, and time to exhaustion improved $56 \%$ and $25 \%$ respectively for the training and control group. The difference of $31 \%$ improvement between groups is accounted for by improvements in strength, but the actual 25\% improvement present in both groups is caused by other factors. Those unexplained factors are possibly neuromuscular adaptations. This article is very important in that it shows that little change in muscle strength $(9.9 \%)$ can result in a large improvement $(56 \%)$ on time to exhaustion. In this study they used maximal strength training. This type of training enables the body to recruit additional muscle fibers to perform the task. A certain aspect of this total recruitment of motor units would result in a better distribution and activation of effort during endurance exercise (Hoff et al. 2002). 
As an alternative, other researchers tried to combine the positive effects of both the strength and endurance training. They developed a new protocol named concurrent strength and endurance training. At first critics mentioned that this type of training will inhibit the development of the benefits of both types of performance. It was thought that since each training requires different pathways for energy provision it would limit the specificity of adapatations to the training (Leveritt et al. 1999).

However others attempted the combination of both types of exercise (Kelly et al. 2008). The researchers investigated adding heavy strength training to an endurance program on improvements on $3 \mathrm{~km}$ run time. It was found that heavy strength training resulted in strength improvements excluding muscle hypertrophy and decrease in relative capillary density. This is a valuable reason for endurance athletes to adopt and incorporate strength training with their endurance training. Endurance athletes do not need the increased muscle mass and need the capillary density to be high. Since strength training did not induce those changes it becomes a training they will use, knowing that the appropriate program design is very important to induce the expected outcomes.

Kelly et al, 2008 investigated the effects of strength training on endurance performance in $3 \mathrm{~km}$ running. Sixteen active women (age range 18-27), were recruited and assigned randomly either to one of three groups: only endurance training (EO), the control group or to concurrent strength and endurance training (CSE). Over a ten week time period the endurance training protocol was designed to improve three kilometer performance. In addition to the endurance training, the CSE group participated in strength training sessions consisting of three sets of five repetitions using exercises that targeted 
the muscles that help perform the running motion (i.e. squats, calf raises, hip extension, hip flexion, hamstring curl, seated row, and bench press).

This study found a difference in the mean times on $3 \mathrm{~km}$ times between groups. The difference in the means was not statistically significant. The CSE group was faster than the EO group, but it was not significant to be reported. Strength levels were the same pre testing but after the training the CSE group showed significantly higher values. The CSE group improved approximately $18 \%$ in the $1 \mathrm{RM}$ of the squat, while the EO group decreased six $6 \%$. After the ten week program both groups observed increases in running economy and $\mathrm{VO}_{2}$ peak however there were no significant difference between them. Measurements did not change and body fat percentage decreased slightly for both groups. This study shows that adding a strength training protocol to endurance training improves strength performance without inhibiting endurance performance. The slight improvement in the CSE times may be explained by improved neuromuscular and biomechanical efficiency that occurs with the addition of strength training.

This study can be used by athletic coaches and long distance athletes to improve their running times, without gaining muscle weight or losing capillaries in the muscles. Training for less time and getting the same results is more efficient than training for extended periods of time to get the same results achievable in less time.

Another recent study that matches observations was completed by Storen et al, 2008. This team of researchers acknowledged three factors on which performance in running is dependant. This paper previously mentioned some of them: lactate threshold, maximal oxygen uptake and running economy. Storen et al, 2008 identified a number of 
studies that used concurrent strength training to improve running economy (RE). All studies (Storen et al. 2008)concluded better RE, after strength training and were accompanied with increases in muscle strength with no significant differences on $\mathrm{VO}_{2}$ peak. A strength training protocol that emphasizes neural adaptations rather than muscular hypertrophy is termed maximal strength training (MST). This protocol implies the use of high loads few repetitions. Storen et al, 2008 mentions in his study that MST protocol has the highest improvements rates on time to exhaustion and running economy. For this reason the aim of his study was to assess the extent of MST, improving squat one maximal repetition, rate of force development, running economy and time to exhaustion at maximal aerobic speed (MAS).

The Storen study included seventeen well-trained runners, assigned to an intervention group ( 4 males and 4 females), and the remaining nine participated as control ( 5 males and 4 females). The subjects were tested on two different days, both groups were tested before and after an 8 week period. Subjects were asked to maintain their exercise habits. The intervention group completed eight week MST program. The MST sessions consisted of 4 sets of 4 maximal repetitions of half squats, 3 times a week.

After eight weeks of training the 1RM significantly increased $33 \%$, running economy at $70 \%$ of $\mathrm{VO}_{2} \max$ increased $5 \%$. More importantly time to exhaustion at MAS increased $21 \%$, similarly to the finding of Hickson et al., 1980. The major finding of this investigation was that MST significantly enhanced running economy and time to exhaustion at maximal aerobic speed. Other measurements remained unchanged including; body mass, $\mathrm{VO}_{2} \max$, lactate threshold velocity, and lactate threshold as percentage of $\mathrm{VO}_{2}$ max. In conclusion this investigation resulted in improvements on 
maximal aerobic speed and this improvement was caused by strength training and explained by improved running economy of $5 \%$ (Storen et al. 2008). This article is the only article to be reviewed in this literature that used one exercise for strength training. The current study used one leg exercise (i.e. leg press) and protocol included high intensity low repetition training.

Last article to be included in this review is the most recent and is written by Ronnestad et al, (2009). The purpose of this study was to examine the effect of heavy strength training on thigh muscle cross-sectional area, performance determinants, and performance in well trained athletes. Twenty three well trained cyclists were recruited and were divided to a control ( $n=7$ males and $n=2$ females) and test group ( $n=11$ males). Both groups maintained their usual endurance training for a 12 week period and the test group performed heavy strength training in addition to the endurance training. Endurance training consist mainly of cycling and some cross country skiing was included. The heavy strength training performed in the test group aimed at leg muscles and was repeated twice a week. Cycling exercises were used to improve cycling performance. Strength training exercises used in the sessions were: half squat, unilateral leg press, unilateral hip flexion, and ankle plantar flexion. After the 12 week intervention there were no significant differences between groups in body mass, thigh muscle cross sectional area, maximal force in isometric half squat, $\mathrm{VO}_{2}$ max or in any of the cycling performance measurements. Strength improvements were observed in the test group but not in the control group. Peak power output in the wingate test increased by $9.4 \%$, in the training group but remained unchanged in the control group. $\mathrm{VO}_{2}$ max increased in both groups with a slightly higher difference for the control group but not a statistically significantly 
different. At $2 \mathrm{mmol}$ concentration of blood lactate power output increased from $242 \mathrm{w}$ to $251 \mathrm{w}$ in the training group. Mean power output in the 40 min maximal effort increased by $6 \%$ for the intervention group and tended to increase by $4.6 \%$ for the control group with no significant change between groups.

The main finding of this study was that the use of strength training with endurance training did not inhibit endurance performance in well trained cyclist. It also showed improvements in endurance performance. Those improvements were more pronounced in the strength and endurance trained group than in the group that only performed endurance training. Muscle strength increased by $21 \%$ and this increase was not accompanied with a significant increase in body weight. From this study it is concluded that neuromuscular adaptations are responsible for improvement in strength after a short term period of strength training (Ronnestad et al.). This study shows that a combination of strength and endurance training can be beneficial for well trained cyclists, and does not inhibit the development of endurance or strength markers.

To summarize, this review has shown that short term gains in muscle strength are caused by neuromuscular adaptations (i.e. learning a specific activation and motor unit recruitment). Muscle hypertrophy, enzyme activities and capillary density remain unchanged in the first 4 weeks of training. Strength training has the potential to significantly increase muscle strength over a short period time with little or no change in body mass. Neural adaptations are therefore the main strength training adaptation. The subjects recruited for the study will participate in 2 weeks of six sessions of strength training protocol. All the mentioned literature showed improvements in endurance performance after undergoing a strength training intervention. These studies also showed 
improved efficiency in performance (i.e. running economy). All studies used at least an 8 week of strength training protocol and showed improvements in endurance performance. Subjects that were recruited in those studies were either well trained cyclist/ runners or were healthy active individuals. The uniqueness of the current study is the attempt to improve high intensity endurance performance (time to fatigue at $100 \%$ of $\mathrm{VO}_{2}$ peak) by the use of short term high intensity training ( 2 weeks with high load and low repetitions). 


\section{CHAPTER THREE: METHODS}

Recruitment:

Twenty three subjects were recruited for the study (female $\mathrm{n}=10$ and male $\mathrm{n}=$ 13). Only 18 subjects completed the study and are included in the data analysis (8 women mean 23.25 years, mean height $65 \mathrm{in}$, mean weight $134.65 \mathrm{lbs}$, and 10 men mean age 22.75 years, mean height 69.6 in, mean weight $168.45 \mathrm{lbs}$ ). Subjects maintained over the six weeks period of the study 1 to 5 hrs of exercise per week. First session included explanation of the study. Subjects signed the informed consent and completed a medical questionnaire. Consented females completed a pregnancy test. Subjects were randomly assigned to a control (C) (total 8 subjects 5 males, 3 females) or to a resistance training (RT) (total 10 subjects 6 males, 4 females) group. Control group participated only in pre and post testing sessions.

\section{Testing Sessions:}

\section{$\mathrm{VO}_{2}$ Peak Test:}

Subjects completed a peak oxygen consumption test on a Monarch cycle ergometer (Monark 818 E Ergomedic, Sweden). The cycle ergometer was calibrated with $2.3 \mathrm{~kg}$ and $4.5 \mathrm{~kg}$ prior to every test. Expired gases were measured with a Parvo (Parvo Medics, Salt Lake city USA, True One 2400 metabolic measurement system) concentrations of $\mathrm{O}_{2}$ and $\mathrm{CO}_{2}$ were measured at 15 seconds intervals. Gases were calibrated with a $16 \% \mathrm{O}_{2}$ and $4 \% \mathrm{CO}_{2}$ tank, than flow was calibrated with a 3 liter syringe. Rating of perceived exertion (RPE) was recorded at the end of each stage, the 
Borg 6-20 scale (Borg 1970) was utilized. Heart rate was recorded at the end of each stage. Subjects had a Polar Electro OY strap around their chest which was connected to a Polar Electro B1 watch that provided constant reading of the heart rate. Temperature and humidity of the lab were recorded with a Davis Perception 11. All subjects were measured and weighed without shoes before the test. Test procedure was then explained. With a mouthpiece and a nose clip on subjects commenced the test. Female subjects started the test with a workload of 40 watts, male subjects started with 100 watts. Workload was increased 20 watts every 3 minutes for the first 3 stages, than every minute until subjects reached their maximum. During the test subjects were instructed to maintain 80 revolutions per minute. Verbal encouragement were provided continuously.

\section{Hydrostatic Weighing:}

Two trials of hydrostatic weighing were recorded, 1) two days after the $\mathrm{VO}_{2}$ max test and 2) at least 3 days prior to the last time to fatigue test. Subjects were asked to fast for $10 \mathrm{hrs}$ prior to the tests. Subjects attended the session with a swimsuit on. Height and weight were measured with the swimsuit on. Subjects were instructed to enter the tank. Water temperature and weight of the chair were recorded. Subjects were instructed to sit in the chair and investigator explained the procedure of the test. Subjects were asked to exhale $75 \%$ of the air in their lungs outside the water than to tuck their head as close as possible to their knees while still exhaling all the air out. Weight of the subjects submersed was then recorded. Subjects had to repeat the procedure till the most accurate 
measurement was obtained. All recorded data was entered to a specialized software. The general formula utilized to assess fat free mass and body fat was by Siri (Siri).

\section{Time to Fatigue test:}

Time to fatigue test was repeated 3 times, 1) at least 4 days after the $\mathrm{VO}_{2} \max$ test. This session was used as a familiarization to the test, 2) exactly 7 days after the first test, 3) the last test was 2 days after the second hydrostatic weighing and at least 4 days after the $2^{\text {nd }}$ leg press test. Three days prior to any of the time to fatigue tests subjects recorded their daily diet, and fasted for 10 hours prior to that session. Subjects were asked to replicate the diet recorded prior to the familiarization test before each of the two remaining tests. Subjects attempted to imitate the diet as much as possible. Diet analysis was not conducted. The workload used for the test was calculated using a regression; including the resistance for the first 3 stages and the $\mathrm{VO}_{2}$ correspondent measurement at 3,6 and 9 minutes respectively. As an example subject $\mathrm{X}$ a male had as a volume for $\mathrm{O} 2$ $1.5 \mathrm{~L} / \mathrm{min}, 1.8 \mathrm{~L} / \mathrm{min}$ and $2.0 \mathrm{~L} / \mathrm{min}$ at 3,6 and 9 minutes of the test. The power utilized at those minutes was 100,120 and 140 watt, a scatter chart was created on excel with these numbers. The linear regression formula that resulted from this scatter was utilized to calculate the appropriate resistance that will induce the highest measurement of $\mathrm{VO}_{2}$ recorded in the $\mathrm{VO}_{2}$ peak test. In this case for subject $\mathrm{X}$ assuming his highest $\mathrm{VO}_{2}$ was $3.0 \mathrm{~L} / \mathrm{min}$ the correspondent resistance would be 217.367 therefore 220 will be the one utilized in the time to fatigue test. In each time to fatigue test subjects cycled to fatigue until they could no longer maintain 80 revolutions per minute. Subjects were stopped on the fourth time they cycled at a pace lower than $75 \mathrm{rpm}$. Each subject had his specific workload determined by $\mathrm{VO}_{2}$ peak test. Investigators did not provide any encouragement, 
and subject was not aware of time. Every minute heart rate and RPE were recorded. At the end of the test subjects immediately sat down for 15 more minutes and their heart rate was recorded every minute. The stop watch used to record the time was EA1 S3300.

\section{Leg Press Test:}

The RT group performed two 1RM pre and post tests on the leg press device (Cybex Plate loaded, Squat press). Subjects were taught how to perform the exercise. They were instructed to place their feet on the same spot every time. They were asked to control the weight on the way down, placing the weight back again on the rack and pushing off again. Verbal encouragements were provided during testing sessions. Adequate rest time of 2 min between sets was provided. Subjects completed a warm-up of an estimated 30 to $50 \%$ 1RM. Incremental increases were applied until a 1RM was achieved. Subjects were provided a 2 min rest between sets.

\section{Training Sessions}

One week after the leg press test training sessions were initiated. The protocol is outlined in the table 1 below. The weights used were $75,80,85,90,95,100,105$, and $110 \%$ of each subject's $1 \mathrm{RM}$. Subjects were asked to complete as many repetitions as possible the last set of each training session. At the beginning of each training session subjects were asked to rate their perceived muscle soreness. In session 6 they performed again the one RM test and after reaching their new maximum, they were asked to realize as many repetitions as possible with their old maximum. Week one training sessions were 3 days apart. Week two training sessions were separated by one day of recovery. Between sessions 5 to 6 subjects had two days of recovery. 


\section{Statistical Analysis}

A two way ANOVA was utilized to compare groups means on time to fatigue

from pre to post intervention. A paired t-test was utilized to analyze strength

improvements from pre to post intervention in the strength training group. 
Table 1: Strength Training Protocol

\begin{tabular}{l|l|l|l}
\hline Session/ Week & Number of Sets & $\begin{array}{l}\text { Number of } \\
\text { Repetitions per set }\end{array}$ & Percentage of 1RM \\
\hline Session 1,Week 1 & 5 & 6 & $\begin{array}{l}\text { Set 1- 75\% } \\
\text { Set 2- 80\% } \\
\text { Set 3 to 5- 85\% }\end{array}$ \\
\hline Session 2, Week 1 & 5 & 5 & $\begin{array}{l}\text { Set 1- 80\% } \\
\text { Set 2- 85\% } \\
\text { Set 3 to 5- 90\% }\end{array}$ \\
\hline Session 3, Week 2 & 6 & 4 & $\begin{array}{l}\text { Set 1- 85\% } \\
\text { Set 2- 90\% } \\
\text { Set 3 to 6- 95\% }\end{array}$ \\
\hline Session 4, Week 2 & 6 & & $\begin{array}{l}\text { Set 1- 90\% } \\
\text { Set 2- 95\% } \\
\text { Set 3 to 6- 100\% }\end{array}$ \\
\hline Session 5, Week 2 & 8 & 3 & $\begin{array}{l}\text { Set 1- 100\% } \\
\text { Set 2- 105\% } \\
\text { Set 3 to 8- 110\% }\end{array}$ \\
\hline
\end{tabular}

Session 6, Week 3, warm-up then incremental increase of weight until new max 1RM is achieved than completion of as many as possible repetitions with the old max. 
Table 2: Details of the Study

\begin{tabular}{l|l|l}
\hline Week/ Days & Control Group & Strength Training Group \\
\hline $1 / 1$ & $\begin{array}{l}\text { Consent/ Medical } \\
\text { Questionnaire/ Pregnancy test } \\
\text { for females }\end{array}$ & $\begin{array}{l}\text { Consent/ Medical } \\
\text { Questionnaire/ Pregnancy test } \\
\text { for females }\end{array}$ \\
\hline $1 / 2$ & VO2 Peak Test & VO2 Peak Test \\
\hline $1 / 3$ & Hydrostatic Weighing 1 & 3- Hydrostatic Weighing 1 \\
\hline $2 / 4$ & $\begin{array}{l}\text { Time to Fatigue test 1/ } \\
\text { Familiarization }\end{array}$ & $\begin{array}{l}\text { Time to Fatigue test 1/ } \\
\text { Familiarization }\end{array}$ \\
\hline $3 / 5$ & Time to Fatigue test 2 & Time to Fatigue Test 2 \\
\hline $3 / 6$ & Nothing & Leg Press Test 1 \\
\hline $4 / 7$ & Nothing & Training Session 1 \\
\hline $4 / 8$ & Nothing & Training Session 2 \\
\hline $5 / 10$ & Nothing & Training Session 3 \\
\hline $5 / 11$ & Nothing & Training Session 4 \\
\hline $6 / 12$ & Nothing & Training Session 5 \\
\hline $6 / 13$ & Nothing & $\begin{array}{l}\text { Training Session 6/ Leg Press } \\
\text { Test 2 }\end{array}$ \\
\hline $6 / 14$ & & Hydrostatic Weighing 2 \\
\hline
\end{tabular}




\section{RESULTS}

Table 5 shows the mean of each test in each group, the standard error and the percentage of improvement. There was no statistically significant difference $(p=.208)$ between training group and control group on Time to Fatigue at $100 \%$ of $\mathrm{VO}_{2}$ Peak. The average mean improvement was $13 \%$ and $1 \%$ for the intervention group and control group respectively. The mean improvement was not statistically significant.

The mean $\mathrm{VO}_{2}$ Peak in the training group was $37.7 \mathrm{ml} / \mathrm{kg} / \mathrm{min}$, whereas for the control group it was $38.3 \mathrm{ml} / \mathrm{kg} / \mathrm{min}$. It was observed that men in general had a higher $\mathrm{VO}_{2}$ Peak number compared to women. The $\mathrm{VO}_{2}$ of men in the training group was 14.1 $\mathrm{ml} / \mathrm{kg} / \mathrm{min}$ higher than that of women and the control group was $10.7 \mathrm{ml} / \mathrm{kg} / \mathrm{min}$ higher than that of women. Tables 3 and 4 describe the average demographics (i.e. age, height, weight, and gender) of participants in each group and detail, $\mathrm{VO}_{2}$ peak measurement, times to exhaustion in test 1 and 2 , and the intensity used for each subject.

Table 6 outlines the mean heart rate and perceived rate of exertion by gender and by group in each time to fatigue test. In the second time to fatigue test women of the resistance training group increased in heart rate and perceived exertion respectively $3.35 \%$ and $5.4 \%$. A decrease in RPE was observed in men and women of the control. Men of the control group had the same mean heart rate pre and post intervention, whereas women had a small increase in heart rate. Men of the training group had a small increase in both measurements. Heart rate increased by $0.42 \%$ and RPE increased by $0.5 \%$. 
Table 7 presents in detail the increase on time to fatigue at $100 \%$ of $\mathrm{VO}_{2}$ Peak. Women of the resistance training group increased $38.96 \%$, whereas women of the control group increased $13.4 \%$. A decrease in time to fatigue was observed in the men control group of $6.35 \%$ and $0.59 \%$ in the resistance training group.

The intervention group significantly improved in strength $(p=.00$ level of significance), the percentage of improvement for each subject is displayed in table 8 . The mean men and women increased $16.95 \%$ and $24.64 \%$ respectively in strength. The leg press increase in strength and the time to fatigue improved performance did not correlate.

Fat free mass was not significantly different between groups. Figure 2 illustrates that both groups slightly increased with a larger increase for the control group. Table 9 details the change per participant and the average per gender per group. Women of the control group increased their muscle mass by $0.12 \%$, where as women of the resistance training group increased by $1.68 \%$. Men on the control group increased by $1.55 \%$ whereas men of the resistance training group decreased by $0.10 \%$. 
Table 3

\begin{tabular}{l|l|l|l|l|l|l}
\hline Subjects\# & Gender & Group & $\begin{array}{l}\text { VO2 Peak } \\
\text { ml/kg/min }\end{array}$ & $\begin{array}{l}\text { Watts for } \\
\text { Time To } \\
\text { Fatigue } \\
\text { Test }\end{array}$ & $\begin{array}{l}\text { Time to } \\
\text { Fatigue } \\
\text { test } \\
\text { number 2 }\end{array}$ & $\begin{array}{l}\text { Time to } \\
\text { Fatigue } \\
\text { Test } \\
\text { number 3 }\end{array}$ \\
\hline 1 & F & Control & 33 & 100 & $542 \mathrm{sec}$ & $640 \mathrm{sec}$ \\
\hline 2 & F & Control & 24.1 & 100 & $230 \mathrm{sec}$ & $241 \mathrm{sec}$ \\
\hline 3 & F & Control & 32.3 & 160 & $115 \mathrm{sec}$ & $125 \mathrm{sec}$ \\
\hline 4 & $\mathrm{~F}$ & Training & 35.4 & 120 & $169 \mathrm{sec}$ & $203 \mathrm{sec}$ \\
\hline 5 & $\mathrm{~F}$ & Training & 28.02 & 140 & $405 \mathrm{sec}$ & $506 \mathrm{sec}$ \\
\hline 6 & $\mathrm{~F}$ & Training & 37.9 & 160 & $324 \mathrm{sec}$ & $377 \mathrm{sec}$ \\
\hline 7 & $\mathrm{~F}$ & Training & 32.6 & 160 & $180 \mathrm{sec}$ & $412 \mathrm{sec}$ \\
\hline 9 & $\mathrm{M}$ & Control & 40.5 & 140 & $264 \mathrm{sec}$ & $268 \mathrm{sec}$ \\
\hline 10 & $\mathrm{M}$ & Control & 52.9 & 280 & $481 \mathrm{sec}$ & $418 \mathrm{sec}$ \\
\hline 11 & $\mathrm{M}$ & Control & 55.4 & 240 & $144 \mathrm{sec}$ & $162 \mathrm{sec}$ \\
\hline 12 & $\mathrm{M}$ & Control & 44.3 & 220 & $366 \mathrm{sec}$ & $316 \mathrm{sec}$ \\
\hline 13 & $\mathrm{M}$ & Control & 41 & 180 & $288 \mathrm{sec}$ & $281 \mathrm{sec}$ \\
\hline 14 & $\mathrm{M}$ & Training & 29.1 & 180 & $316 \mathrm{sec}$ & $332 \mathrm{sec}$ \\
\hline 15 & $\mathrm{M}$ & Training & 46.3 & 240 & $287 \mathrm{sec}$ & $274 \mathrm{sec}$ \\
\hline 16 & $\mathrm{M}$ & Training & 43.9 & 220 & $424 \mathrm{sec}$ & $392 \mathrm{sec}$ \\
\hline 17 & $\mathrm{M}$ & Training & 35.2 & 180 & $440 \mathrm{sec}$ & $510 \mathrm{sec}$ \\
\hline 18 & $\mathrm{M}$ & Training & 44.4 & 240 & $349 \mathrm{sec}$ & $292 \mathrm{sec}$ \\
\hline & $\mathrm{M}$ & Training & 52.8 & 220 & $294 \mathrm{sec}$ & $297 \mathrm{sec}$ \\
\hline
\end{tabular}


Table 4

\begin{tabular}{l|l|l|l|l|l}
\hline Groups & Gender & $\begin{array}{l}\text { Average } \\
\text { Age }\end{array}$ & $\begin{array}{l}\text { Average } \\
\text { Height Inch }\end{array}$ & $\begin{array}{l}\text { Average } \\
\text { Weight LBS }\end{array}$ & $\begin{array}{l}\text { Average } \\
\text { VO2 Peak } \\
\mathrm{ml} / \mathrm{kg} / \mathrm{min}\end{array}$ \\
\hline \multirow{2}{*}{ Control } & Females & 24 & 64.25 & 131.2 & 29.8 \\
\cline { 2 - 6 } & Males & 23 & 69.4 & 163.6 & 40.5 \\
\hline \multirow{2}{*}{ Training } & Females & 22.5 & 65.68 & 138.1 & 32.26 \\
\cline { 2 - 6 } & Males & 22.5 & 69.8 & 173.3 & 46.36 \\
\hline
\end{tabular}


Table 5

\begin{tabular}{|c|c|c|c|c|}
\hline Group & $\begin{array}{l}\text { Time to } \\
\text { Fatigue \# }\end{array}$ & Mean & Standard Error & $\begin{array}{l}\text { Percent } \\
\text { Improvement }\end{array}$ \\
\hline \multirow[t]{2}{*}{ Training group } & 1 & 318.800 & 38.563 & \multirow[t]{2}{*}{$\sim 13 \%$} \\
\hline & 2 & 359.500 & 41.325 & \\
\hline \multirow[t]{2}{*}{ Control Group } & 1 & 303.750 & 43.115 & \multirow[t]{2}{*}{$\sim 1 \%$} \\
\hline & 2 & 306.375 & 46.203 & \\
\hline
\end{tabular}


Table 6

\begin{tabular}{l|l|l|l|l}
\hline \multirow{2}{*}{ Groups } & $\begin{array}{l}\text { Time To } \\
\text { Fatigue Test }\end{array}$ & Gender & $\begin{array}{l}\text { Average end of } \\
\text { Test Heart Rate }\end{array}$ & $\begin{array}{l}\text { Average end of } \\
\text { Test Rate of } \\
\text { Perceived } \\
\text { Exertion }\end{array}$ \\
\hline \multirow{2}{*}{ Control } & \multirow{4}{*}{ Test number 1 } & Females & 180 & 18.6 \\
\cline { 3 - 5 } & & Males & 183.6 & 19 \\
\cline { 3 - 5 } Training & Females & 173 & 18.25 \\
\cline { 3 - 5 } Control & Males & 186.3 & 19.5 \\
\hline \multirow{2}{*}{ Training } & \multirow{2}{*}{ Test number 2 } & Females & 183 & 18.3 \\
\cline { 3 - 5 } & & Males & 183.6 & 18.8 \\
\cline { 3 - 5 } & & Females & 179 & 19.5 \\
\cline { 3 - 5 } & Males & 187.1 & 19.6 \\
\hline
\end{tabular}




\section{Table 7}

\begin{tabular}{l|l|l|l|l}
\hline \multirow{2}{*}{ Group } & Gender & $\begin{array}{l}\text { Time to Fatigue } \\
1\end{array}$ & $\begin{array}{l}\text { Time to Fatigue } \\
2\end{array}$ & \% of change \\
\hline \multirow{2}{*}{ Control } & Females & 295.6 & 335.3 & $13.4 \%$ \\
\cline { 2 - 5 } & Males & 308.6 & 289 & $-6.35 \%$ \\
\hline \multirow{2}{*}{ Training } & Females & 269.5 & 374.5 & $38.96 \%$ \\
\cline { 2 - 5 } & Males & 351.6 & 349.5 & $-0.59 \%$ \\
\hline
\end{tabular}


Table 8

\begin{tabular}{|c|c|c|c|c|c|}
\hline \multicolumn{2}{|c|}{$\begin{array}{l}\text { Training Group } \\
\text { Subjects/ } \\
\text { Genders }\end{array}$} & $\begin{array}{l}\text { Leg Press Test } \\
1 \text { in pounds }\end{array}$ & $\begin{array}{l}\text { Leg Press Test } \\
2 \text { in pounds }\end{array}$ & Percent Change & $\begin{array}{l}\text { Average } \\
\text { Percentage per } \\
\text { genders }\end{array}$ \\
\hline 4 & $\mathrm{~F}$ & 460 & 550 & $19.57 \%$ & \multirow{4}{*}{$24.64 \%$} \\
\hline 5 & $\mathrm{~F}$ & 410 & 550 & $34.15 \%$ & \\
\hline 6 & $\mathrm{~F}$ & 470 & 520 & $10.64 \%$ & \\
\hline 7 & $\mathrm{~F}$ & 380 & 510 & $34.21 \%$ & \\
\hline 13 & $\mathrm{M}$ & 680 & 950 & $39.71 \%$ & \multirow{6}{*}{$16.95 \%$} \\
\hline 14 & $\mathbf{M}$ & 510 & 580 & $13.73 \%$ & \\
\hline 15 & $\mathrm{M}$ & 990 & 1100 & $11.11 \%$ & \\
\hline 16 & $\mathrm{M}$ & 910 & 970 & $6.59 \%$ & \\
\hline 17 & $M$ & 930 & 1080 & $16.13 \%$ & \\
\hline 18 & $\mathrm{M}$ & 900 & 1030 & $14.44 \%$ & \\
\hline
\end{tabular}


Table 9

\begin{tabular}{l|l|l|l|l|l}
\hline $\begin{array}{l}\text { Group and } \\
\text { Genders }\end{array}$ & $\begin{array}{l}\text { Numbe } \\
\mathrm{r}\end{array}$ & $\begin{array}{l}\text { Fat Free Mass } \\
1\end{array}$ & $\begin{array}{l}\text { Fat Free Mass } \\
2\end{array}$ & $\begin{array}{l}\text { Percent } \\
\text { change }\end{array}$ \\
\hline Control & $\mathrm{F}$ & 1 & 95.78 & 97.61 & $1.91 \%$ \\
\hline Control & $\mathrm{F}$ & 2 & 102.7 & 99.23 & $-3.37 \%$ \\
\hline Control & $\mathrm{F}$ & 3 & 98.3 & 100.12 & $1.85 \%$ \\
\hline Training & $\mathrm{F}$ & 4 & 74.86 & 76.43 & $2.09 \%$ \\
\hline Training & $\mathrm{F}$ & 5 & 119.44 & 119.66 & $0.18 \%$ \\
\hline Training & $\mathrm{F}$ & 6 & 111.69 & 116.27 & $4.1 \%$ \\
\hline Training & $\mathrm{F}$ & 7 & 103.32 & 103.7 & $0.36 \%$ \\
\hline Control & $\mathrm{M}$ & 8 & 105.44 & 11.03 & $5.3 \%$ \\
\hline Control & $\mathrm{M}$ & 9 & 157.14 & 157.46 & $0.2 \%$ \\
\hline Control & $\mathrm{M}$ & 10 & 126.8 & 124.34 & $-1.94 \%$ \\
\hline Control & $\mathrm{M}$ & 11 & 160.65 & 166.95 & $3.92 \%$ \\
\hline Control & $\mathrm{M}$ & 12 & 135.29 & 135.69 & $0.29 \%$ \\
\hline Training & $\mathrm{M}$ & 13 & 155.35 & 152.33 & $-1.94 \%$ \\
\hline Training & $\mathrm{M}$ & 14 & 152.26 & 153.56 & $0.85 \%$ \\
\hline Training & $\mathrm{M}$ & 15 & 144.17 & 148.2 & $2.79 \%$ \\
\hline Training & $\mathrm{M}$ & 16 & 141.53 & 141.22 & $-0.21 \%$ \\
\hline Training & $\mathrm{M}$ & 17 & 149.52 & 150.72 & $0.8 \%$ \\
\hline Training & $\mathrm{M}$ & 18 & 116.38 & 112.98 & $-2.92 \%$ \\
\hline
\end{tabular}




\section{Figure1}

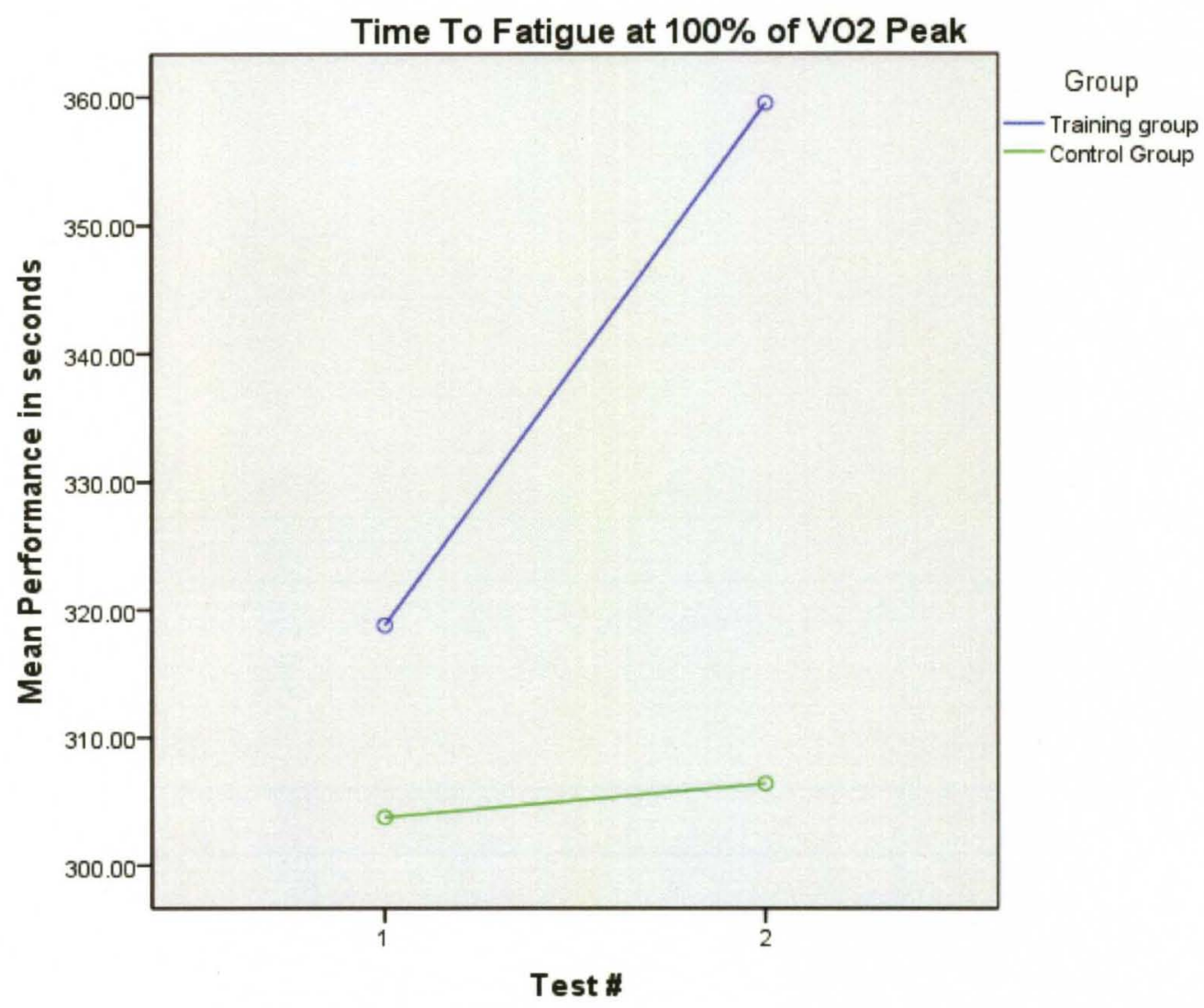

There was no statistical significant difference on time to fatigue between groups $(\mathrm{p}=.206)$ 
Figure 2

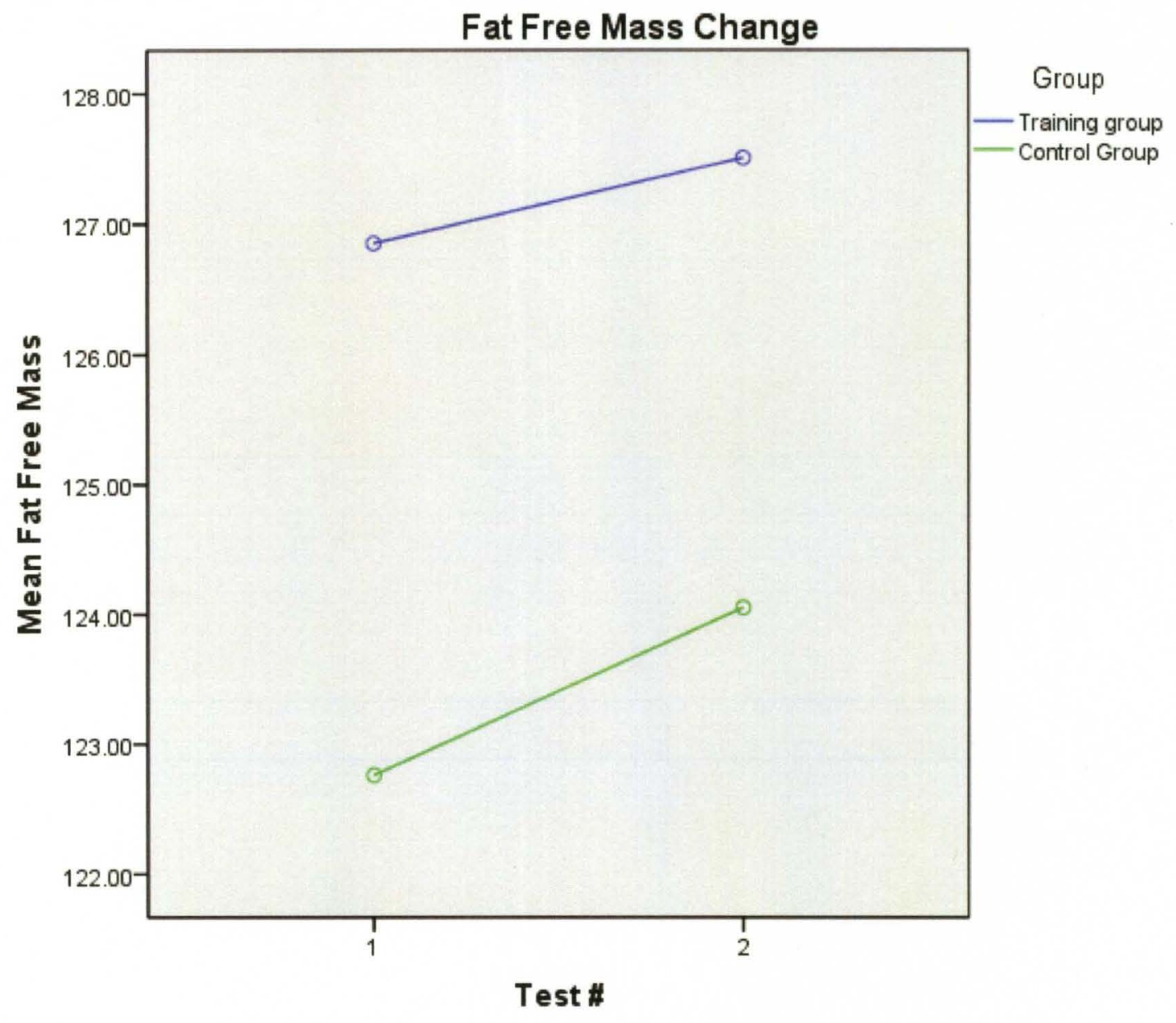




\section{DISCUSSION}

The purpose of the 2 week strength training was to attempt to induce a difference on time to fatigue at maximal aerobic performance. The major findings of this current study were: a) time to fatigue did not statistically significantly change with the implementation of short term high intensity training, b) the means of the Time to Fatigue improved $13 \%$ in the intervention group although not statistically significant there was apparently a practical improvement, c) it appears from the results of this study that women improved the most on time to fatigue and were affected by the strength training program more than men c) short term strength training significantly increased 1RM results on the leg press device, from pre to post in the intervention group. Five sessions of resistance strength training has a great potential in improving strength performance.

The hypothesis based of the pilot study of Lambert et al 2009 (in review) was if strength improvements did not induce increased time to fatigue performance, it would be possible to conclude that fat free mass is a main factor that affects performance at maximal aerobic output. From the results of this study it is impossible to draw clear conclusions whether or not fat free mass is responsible for sustaining performance at maximal $\mathrm{VO}_{2}$ peak. There was no statistical significant difference on time to fatigue between the control and the resistance training group. But the mean women time to fatigue in both groups increased respectively $38.96 \%$ and $13.4 \%$ in the resistance training group and the control group. Based on this information and the fact that men did not 
improve in both groups it would be wrong to conclude that fat free mass is a strong predictor of performance in time to fatigue at $100 \%$ of maximal aerobic effort.

When comparing the resistance training group with the control group the mean time to fatigue was increased by $12 \%$. In the control group women increased in time to fatigue but men decreased in time to fatigue. In the training group men decreased by $0.59 \%$ where as women increased $38.96 \%$. It seems from this data that women were more influenced by this type of training. Still the men of the resistance training group did not have as strong as decrease as the control group, implying in a way that the training sessions were effective with the men to lower the loss in the time to fatigue test. From the data collected it is not possible to explain why men performed less than women although knowing that men usually perform better in short term high intensity exercise than women, because of larger fast twitch fibers, higher glycolytic enzyme activity and larger storage of muscle glycogen (Jansson and Kaijser 1982; Staron et al. 2000).

The results of this study indicate that improvements in strength were not correlated with improvement in time to fatigue even when comparing the results in between genders. It was mentioned before that women improved $38.96 \%$ on time to fatigue. This is a very high increase in just 2 weeks of training. Women also improved $24.64 \%$ in strength $8 \%$ more than men. Women seem to have benefited from the training more than men. Notably women are better able to adapt to exercises that specifically induces neural muscle adaptations (Pansarasa et al. 2009). A possible reason for why men might have not increased in strength as much women is that men already had higher strength levels and the possibility to increase this performance is harder and requires more training. Whereas women starting with lower weight, less than half of what some 
men were capable of carrying had a larger window for improvement. A key aspect of this study was that a larger improvement in strength induced a larger improvement on time to fatigue in women of the resistance training group.

The other tested hypothesis was strength training improves performance at $100 \%$ of $\mathrm{VO}_{2}$ Peak by neuromuscular adaptations (i.e. improved muscle activation and motor unit recruitment). This hypothesis cannot be supported or denied since some subjects improved in both groups and no statistical significant difference was found. To refute or support this hypothesis a larger group needs to be tested and included in the analysis. This study resulted in a $13 \%$ improvement in the intervention group. This practical improvement occurred mainly by neuromuscular adaptation. It's not possible with the collected data set to conclude that the improvement was specifically neuromuscular adaptations. But it is known from review of literature that strength training improves neurologic factors and increases lactate threshold (Folland et al. 2007; Jung and Jung 2003). Strength training applied for an extended period will cause hypertrophy, increase of muscle glycogen and some decreases in markers of endurance performance (Leveritt et al. 1999). This study was designed to induce improvements in the neurologic factors. This is why knowing from the existent literature that muscle hypertrophy occurs after 3 to 4 week of training, and that lactate threshold also happens after a relatively longer period is important for this study (Andersen and Aagaard ; Jung and Jung 2003; Marcinik et al. 1991). Because of this thought process other factors can be eliminated and it can be concluded that the strength gains were strictly related to neuromuscular adaptations.

Exercising at a high intensity increases the rate of production of lactate which inhibits performance when threshold is reached (Sesbo et al.). Commonly strength 
training has been known to increase the capacity of individuals to exercise with higher concentrations of lactate (Leveritt et al. 1999). This might be a reason why some subjects on this study improved. Increases in lactate threshold occur after extended periods of strength training(Leveritt et al. 1999). Lactate threshold was not measured during the time to fatigue tests it is not the main marker that caused this improvement on time to fatigue with two weeks of training.

This study found no significant pre intervention difference in fat free mass between groups or from pre to post intervention. The observation that muscle mass did not change, implies that strength training did not induce hypertrophy of the muscle. Therefore the gains in strength were not the result of gains in muscle mass. Since the strength training program was not long enough to induce increases in lactate threshold, or hypertrophy of the muscle, neuromuscular adaptations remains the factor that might have induced this change. The fact that fat free mass did not change supports the hypothesis that neuromuscular adaptations occurred and that they were responsible for the increase in performance.

Interestingly the females of the experimental group seem to have exerted more effort in the last time to fatigue test. Heart rate and rate of perceived exertion increased $3.35 \%$ and $5.4 \%$ respectively from pre to post testing. Heart rate and rate of perceived exertion of the men was more consistent with smaller changes, proposing that men exerted the maximal effort at each time to fatigue test. From the existing data it is impossible to justify this phenomenon. No scientific evidence exists to support any theory that would be proposed to explain the phenomenon. 


\section{Limitations of the study}

The most important limitation of this study was its small sample size not strong conclusions can be made from the results. Control and training groups need to be larger to provide more data for analysis.

Quantifying motivation is a key limitation for the time to fatigue test. Individuals might have exerted more effort on one of the time to fatigue tests. The time to fatigue test was presented and explained with the methodology. To limit variability the Investigator explained the importance of the subject performing their best every time and no encouragements were provided during the test.

Although participants were asked to work out 1 to 5 hrs a week keeping the same habits they had prior to enrolling to the study there were no strict way to ensure subjects' compliance with the rules of the study. It is possible that subjects would have changed their diets or habits during the study and did not report to investigator, this might have changed the way they reacted to the intervention. Subjects from the control group might have started training and improved as a result of their training.

The 1RM leg press test was not applied to the control group. This limits the findings of this study. It would have been interesting and beneficial to know if the control group would change in performance after practicing testing trials.

The leg press device utilized for the training did not provide the same range of motion for all the subjects. The tallest from the subjects were reaching 90 degree angle while pressing down, whereas shorter subjects were reaching 110,120 , or 130 degrees. Not going as low as 90 degrees might have inhibited the development of strength in 
specific active muscles in the cycling motion. When utilizing a smaller range of motion subjects are capable to move heavier weights for a higher number of repetitions.

Other researchers used one strength training exercise and noted an improvement of strength after 8 weeks of training. This improvement in strength resulted in improvements in endurance performance. Time to fatigue increased as a result of strength improvements. This is the first study to use 2 weeks of strength training in attempt to change maximal aerobic effort. To maximize the neural adaptations it might have been beneficial to include more than one strength training exercise in the protocol of the study. Since only one exercise was utilized subjects were always asked to perform as many repetitions as possible in the last of each training session.

The cycle ergometer used for testing was dependent on the accuracy of the investigator. The correct measurement was hard to be applied. Since the machine provides increments of 0.5 smaller increases were harder to be adjusted. This is why it was decided to round up the resistance used for the time to fatigue test to $0.00,0.25,0.5$ or 0.75 . As a result some subjects ended up exercising with a little harder resistance than what they should have been exercising with. Exercising with a higher resistance might have induced primarily anaerobic performance increasing faster the production of lactate. The fast increase of lactate might have resulted in muscle fatigue quicker than if the right resistance was applied. Human error of investigator might have resulted in lower results. 


\section{CONCLUSION}

The purpose of this study was to examine the effects of 2 weeks of high intensity strength training on time to fatigue at $100 \%$ of $\mathrm{VO}_{2}$ peak. The major finding of this study was that neuromuscular adaptations did not significantly alter performance at high intensity exercise. Although not statistically significant the mean time to fatigue improved $13 \%$ in the resistance training group. Women of the resistance training group had the largest gains in strength and time to fatigue, $24.64 \%$ and $38.96 \%$ respectively. Men of the resistance training group gained $16.95 \%$ in muscle strength but did not improve in time to fatigue. Women of the control group improved $13.4 \%$ on time to fatigue. For future studies a larger sample size in genders and groups should be included in order to find significant results. There is an obvious need for additional research on the specifics of adaptations of genders. 


\section{REFERENCES}

Andersen, J. L., \& Aagaard, P. Effects of strength training on muscle fiber types and size; consequences for athletes training for high-intensity sport. Scandinavian Journal of Medicine \& Science in Sports, 20 Supplement(2), 32-38.

Ball, D., Greenhaff, P. L., \& Maughan, R. J. (1996). The acute reversal of a diet-induced metabolic acidosis does not restore endurance capacity during high-intensity exercise in man. [Clinical Trial

Randomized Controlled Trial

Research SuAndersen JL, Aagaard P Effects of strength training on muscle fiber types and size; consequences for athletes training for high-intensity sport. Scandinavian Journal of Medicine \& Science in Sports 20 Supplement: 32-38

Ball D, Greenhaff PL, Maughan RJ (1996) The acute reversal of a diet-induced metabolic acidosis does not restore endurance capacity during high-intensity exercise in man. European Journal of Applied Physiology \& Occupational Physiology 73: 105-112

Bangsbo J, Gollnick PD, Graham TE, Juel C, Kiens B, Mizuno M, Saltin B (1990) Anaerobic energy production and $\mathrm{O} 2$ deficit-debt relationship during exhaustive exercise in humans. J Physiol (Lond) 422: 539-559

Bemben MG, Murphy RE (2001) Age related neural adaptation following short term resistance training in women. J Sports Med Phys Fitness 41: 291-299

Borg G (1970) Perceived exertion as an indicator of somatic stress. Scand J Rehabil Med 2: $92-98$

Brooks GA, Mercier J (1994) Balance of carbohydrate and lipid utilization during exercise: the "crossover" concept. Journal of Applied Physiology 76: 2253-2261

Coyle EF (1995) Substrate utilization during exercise in active people. Am J Clin Nutr 61: $968 \mathrm{~S}-979 \mathrm{~S}$

Del Balso C, Cafarelli E, Del Balso C (2007) Adaptations in the activation of human skeletal muscle induced by short-term isometric resistance training. Journal of Applied Physiology 103: 402-4 
Folland JP, Williams AG, Folland JP, Williams AG (2007) The adaptations to strength training : morphological and neurological contributions to increased strength. Sports Med 37: $145-168$

Fry AC, Fry AC (2004) The role of resistance exercise intensity on muscle fibre adaptations. Sports Med 34: 663-679

Hakkinen K, Kallinen M, Linnamo V, Pastinen UM, Newton RU, Kraemer WJ (1996) Neuromuscular adaptations during bilateral versus unilateral strength training in middleaged and elderly men and women. Acta Physiol Scand 158: 77-88

Hanon C, Leveque JM, Thomas C, Vivier L (2008) Pacing strategy and VO2 kinetics during a 1500-m race. Int J Sports Med 29: 206-211

Hardman AE, Williams C, Boobis LH (1987) Influence of single-leg training on muscle metabolism and endurance during exercise with the trained limb and the untrained limb. J Sports Sci 5: 105-116

Hickson RC, Dvorak BA, Gorostiaga EM, Kurowski TT, Foster C (1988) Potential for strength and endurance training to amplify endurance performance. Journal of Applied Physiology 65: 2285-2290

Hickson RC, Rosenkoetter MA, Brown MM (1980) Strength training effects on aerobic power and short-term endurance. Med Sci Sports Exerc 12: 336-339

Hill DW, Alain C, Kennedy MD, Hill DW, Alain C, Kennedy MD (2003) Modeling the relationship between velocity and time to fatigue in rowing. Med Sci Sports Exerc 35: 2098-2105

Hoff J, Gran A, Helgerud J (2002) Maximal strength training improves aerobic endurance performance. Scandinavian Journal of Medicine \& Science in Sports 12: 288-295

Jansson E, Kaijser L (1982) Effect of diet on muscle glycogen and blood glucose utilization during a short-term exercise in man. Acta Physiol Scand 115: 341-347

Jensen L, Bangsbo J, Hellsten Y (2004) Effect of high intensity training on capillarization and presence of angiogenic factors in human skeletal muscle. J Physiol (Lond) 557: 571582

Judge LW, Moreau C, Burke JR, Judge LW, Moreau C, Burke JR (2003) Neural adaptations with sport-specific resistance training in highly skilled athletes. J Sports Sci 21: $419-427$

Jung AP, Jung AP (2003) The impact of resistance training on distance running performance. Sports Med 33: 539-552 
Kelly CM, Burnett AF, Newton MJ, Kelly CM, Burnett AF, Newton MJ (2008) The effect of strength training on three-kilometer performance in recreational women endurance runners. J Strength Cond Res 22: 396-403

Lambert CP, Evans WJ, Lambert CP, Evans WJ (2005) Adaptations to aerobic and resistance exercise in the elderly. Rev Endocr Metab Disord 6: 137-143

Lambert CP, Greenhaff PL, Ball D, Maughan RJ (1993) Influence of sodium bicarbonate ingestion on plasma ammonia accumulation during incremental exercise in man. European Journal of Applied Physiology \& Occupational Physiology 66: 49-54

Leveritt M, Abernethy PJ, Barry BK, Logan PA (1999) Concurrent strength and endurance training. A review. Sports Med 28: 413-427

Marcinik EJ, Potts J, Schlabach G, Will S, Dawson P, Hurley BF (1991) Effects of strength training on lactate threshold and endurance performance. Med Sci Sports Exerc 23: $739-743$

McCarthy JP, Pozniak MA, Agre JC, McCarthy JP, Pozniak MA, Agre JC (2002) Neuromuscular adaptations to concurrent strength and endurance training. Med Sci Sports Exerc 34: 511-519

Pansarasa O, Rinaldi C, Parente V, Miotti D, Capodaglio P, Bottinelli R, Pansarasa O, Rinaldi C, Parente V, Miotti D, Capodaglio P, Bottinelli R (2009) Resistance training of long duration modulates force and unloaded shortening velocity of single muscle fibres of young women. J Electromyogr Kinesiol 19: e290-300

Putman CT, Jones NL, Hultman E, Hollidge-Horvat MG, Bonen A, McConachie DR, Heigenhauser GJ (1998) Effects of short-term submaximal training in humans on muscle metabolism in exercise. Am J Physiol 275: E132-139

Renoux JC, Petit B, Billat V, Koralsztein JP (2000) Calculation of times to exhaustion at 100 and $120 \%$ maximal aerobic speed. Ergonomics 43: 160-166

Ronnestad BR, Hansen EA, Raastad T, Ronnestad BR, Hansen EA, Raastad T Effect of heavy strength training on thigh muscle cross-sectional area, performance determinants, and performance in well-trained cyclists. Eur J Appl Physiol 108: 965-975

Sesbo, x00Fc, x00E, Guincestre JY, B. Muscular fatigue. Ann Readapt Med Phys 49: 257-264

Simoneau JA, Bouchard C (1989) Human variation in skeletal muscle fiber-type proportion and enzyme activities. Am J Physiol 257: E567-572 
Siri WE Body composition from fluid spaces and density: analysis of methods. 1961. Nutrition 9: 480-491; discussion 480

Staron RS, Hagerman FC, Hikida RS, Murray TF, Hostler DP, Crill MT, Ragg KE, Toma $\mathrm{K}$ (2000) Fiber type composition of the vastus lateralis muscle of young men and women. J Histochem Cytochem 48: 623-629

Storen O, Helgerud J, Stoa EM, Hoff J, Storen O, Helgerud J, Stoa EM, Hoff J (2008) Maximal strength training improves running economy in distance runners. Med Sci Sports Exerc 40: 1087-1092

Tarnopolsky MA, Tarnopolsky MA (2008) Sex differences in exercise metabolism and the role of 17-beta estradiol. Med Sci Sports Exerc 40: 648-654

Tesch PA (1988) Skeletal muscle adaptations consequent to long-term heavy resistance exercise. Med Sci Sports Exerc 20: S132-134

Tesch PA, Colliander EB, Kaiser P (1986) Muscle metabolism during intense, heavyresistance exercise. European Journal of Applied Physiology \& Occupational Physiology 55: $362-366$

Tesch PA, Komi PV, Hakkinen K (1987) Enzymatic adaptations consequent to long-term strength training. Int J Sports Med 8 Suppl 1: 66-69

Tesch PA, Larsson L (1982) Muscle hypertrophy in bodybuilders. European Journal of Applied Physiology \& Occupational Physiology 49: 301-306

Tesch PA, Thorsson A, Kaiser P (1984) Muscle capillary supply and fiber type characteristics in weight and power lifters. Journal of Applied Physiology: Respiratory, Environmental \& Exercise Physiology 56: 35-38

Wakayoshi K, Yoshida T, Ikuta Y, Mutoh Y, Miyashita M (1993) Adaptations to six months of aerobic swim training. Changes in velocity, stroke rate, stroke length and blood lactate. Int J Sports Med 14: 368-372 support, Non-U.S. Gov't]. European Journal of Applied Physiology \& Occupational Physiology, 73(1-2), 105-112. 


\section{CURICULUM VITAE}

\section{Patrick Abi Nader, M.S. Expected December 2010}

\section{$\underline{\text { Education }}$}

M.S. Expected December 2010, Major- Exercise Physiology, University of Louisville

Thesis Topic: "Effects of Short-term, High-Force Resistance Training on High-Intensity Exercise Capacity". Supervisors: Dr. Charles Lambert/ Dr. Dean Jacks

University of Balamand (Lebanon), T.D. (Teaching Diploma) 2008 Major- Physical Education

University of Balamand (Lebanon), B.A. 2007 Major- Physical Education

\section{Work Experience}

2009- University Of Louisville Researcher

Present Schools of Nursing \& Exercise Physiology

Louisville, KY

Organized, supervised and trained research team of data collectors. Collected pre- and post-intervention data on participants. Scheduled appointments and tested participants.

2009- Get Healthy Now $\quad$ Fitness Specialist

Present University of Louisville Louisville, KY

Responsible for the development of exercise routines, and health fitness assessments of University faculty and staff. Performed health fitness assessments consisting of: Biometric screenings, cardiovascular testing, body composition, musculoskeletal condition, flexibility, and anthropometric measurements. Responsible for marketing and promoting charity events such as Relay For Life. Provided personal consultations and training.

\section{0- Dive the Med Dive Master}

Summer Safra, Lebanon

Trained, supervised, and assessed divers of various ages in a variety of learning environments including open water advanced diving and rescue diving courses. Responsible for developing dive plans, briefing divers about dive details including emergency procedures, ensuring group safety and implementing dive. Led scuba groups in a variety of dives including: Night dives, shipwreck dives, deep dives, and multilevel dives. Divers were briefed about: the dive site, the maximum depth, the duration, the air 
consumption, the emergency procedures, the entry and exit points, and the formation of the group under water. Successfully taught and assisted in teaching Open water, Advanced, and Rescue diving classes.

2008- Dive the Med

Fall Safra, Lebanon

Rescue Diver/ Dive center manager

Responsible for prevention of accidents and injuries. Provided support for dive leader. Assisted scuba instructor in instructional dives. Managed the dive center, handled payments (equipment rental and fun dives) and cleanliness of the dive center.

2007-2008 Adma International School Physical Education Instructor Mount Lebanon, Lebanon

Prepared lesson plans and implemented them in class sessions. Classes taught were $\mathrm{Kg} 2$, $\mathrm{Kg} 1$, Grades 1-5 and 9. Maintained order in class and playground. Developed and organized off-campus and extracurricular activities for the students.

2007

Al Jazeera Kids

Project Manager

Chekka, Lebanon

Prepared and performed windsurfing basic skill class. Teaching sessions were filmed and broadcasted in the Arab countries on the TV channel "Al Jazeera Kids".

2005-2006 Balamand School Swimming Instructor

Koura, Lebanon

Taught basic swimming skills for students aged of 4 to 12 .

\section{Research Experience}

University of Louisville:

2009-2010 Exercise Physiology Dr. Charles Lambert/ Dr. Dean Jacks

Thesis: "Effects of Short-term, High-Force

Resistance Training on High-Intensity Exercise Capacity"

Responsible for; recruiting, testing, training, of participants and collecting and interpreting data on control and experimental groups. Testing sessions included: submaximal $\mathrm{VO}_{2}$ test on a cycle ergometer, measurement of fat free mass by hydrostatic weighing, leg press maximal repetition test, and time to fatigue test on a cycle ergometer.

2010 School of Nursing Dr. Robert Topp

"The Effects of Dose and Application of Menthol on Local and Systemic Strength and Blood Flow" 
Responsible for Data Collection. Using the Doppler blood flow was measured at the femoral artery. Assumed the responsibility of a research technician.

2010

$$
\begin{aligned}
& \text { School of Nursing Dr. Robert Topp } \\
& \text { "The Effects of Combined Topical Menthol and Ice } \\
& \text { on Distal Blood Flow" }
\end{aligned}
$$

Assumed the responsibilities of a research technician. Used the Doppler to measure blood flow at the radial artery.

2010

$$
\text { Exercise Physiology Dr. Brian Jones/ Colleague Tony Jouaux }
$$

"Aerobic and Anaerobic Performance Changes Following Three Training Phases in Men's Soccer Players"

Assisted main researcher in data collection on college soccer players.

2009-2010 School of Nursing

\section{Fit Into College I and II}

Dr. Robert Topp

Responsible for; scheduling and testing subjects, collecting data, training new research team in testing procedures.

$2009 \quad$ Exercise Physiology Dr. Charles Lambert

"The Effect of Gender on Time to Fatigue at $100 \%$ of VO2 Peak"

Assistant to main researcher. Helped with data collection.

\section{Presentations:}

Topp, R., Winchester, L., Schilero, J., Abi-Nader, P., Gibb, A., \& Jacks, D.E. PhD. "The Effects of Dose and Application of Menthol on Local and Systemic Strength and Blood Flow." TheraBand Research Advisory Council, Athens, Greece, July 19-21, 2010.

Topp, R., Ledford, E.R., Abi-Nader, P., Schilero, J., Jacks, D.E., PhD. "The Effects of Combined Topical Menthol and Ice on Distal Blood Flow." TheraBand Research Advisory Council, Athens, Greece, July 19-21, 2010.

Abi-Nader, P., Lambert, C.P., Winchester, L., Jacks, D.E. "The Effect of Gender on Time to Fatigue at 100\% V02 Peak." Southeast ACSM (American College of Sports Medicine) Annual meeting, Greenville SC, February 11-13, 2010

Spellman, F., Abi Nader, P. "Heat Related Injuries and Prevention." Department of Human Resources, University of Louisville, July 2009.

\section{Teaching experience}

Instructor: HSS 184 Healthy Lifestyles 1, Department of Health and Sports Sciences, University of Louisville, KY 
Teaching Assistant: Underwater Skills: Open Water, Department of Physical Education, American University of Technology, Halat, Lebanon

2006-2007

Physical

2005-2006

2006-2007

2008

2005-2006
Teaching Assistant: Introduction to Windsurfing, Department of Education, University of Balamand

Teaching Assistant: Introduction to Snowboarding, Department of Physical Education, University of Balamand

Instructor: Rock Climbing: Basic Skills, La Reserve

Instructor: Swimming teacher, Balamand School

\section{Volunteer work}

Fall 2010- Present Founding member of Louisville I.D.E.A.L.S. a program that is designed to use sport for peace, conflict resolution and promotion of positive social behavioral change. My main responsibility is implementing a street soccer team for homeless kids. Organized and planned; trainings, fundraising events and cultural events.

\section{Awards and Certifications}

- University of Louisville College of Education and Human Development, Scholarship for Academic Achievement, September 2010

- Dive Master, NAUI (National Association for Underwater Instructors), June 2010

- Scholarship for Academic Achievement, January 2010

- Heartsaver CPR, American Heart Association, October 2008

- Rescue Diver, IANTD (International Association of Nitrox and Technical Divers), 2008

- Rock Climbing Monitor, "L'Ecole Francaise d'Escalade", "Mousqueton D'Argent" 2008

- "Best Athlete: Water Polo", University of Balamand, 2008

- "Athlete of the Year", University of Balamand, 2007-2008

- "Best Athlete: Swimming", University of Balamand, 2006-2007

- "Outstanding Event" Physical Education Club, University of Balamand, 2007

- “Strongest Man Under 90kg" University of Balamand, 2007

- "Best Athlete: Swimming" University of Balamand, 2005-2006

- Certified by the Lebanese Federation of Volleyball; International Statistics 2006

- Junior Lifeguard, YMCA, 2003

- First Aid, Certified, Lebanese Red Cross, 2003

- Received two certifications Karate Seminar, I.S.K.F. (International Shotokan Karate Federation), 1998-1999

\section{Languages \& Skills}

Arabic: Native 
French: Native

English: Fluent

Computer knowledge: SPSS, Microsoft: Word, Excel, Power Point, and Internet

\section{Extra Curricular Activities}

Physical Education Society, University of Balamand 2006-2007 President

Swimming, swam for Rimal resort 2003-2008 and part of the College team 2005-2008

Karate, played for I.S.K.F., 1996-2003

Judo, Part of the school team 1995-2001

Badminton, Played for college team, 2005-2008

Soccer, played for the soccer college team, 2005-2008

Water Polo, part of the college team, and Rimal Resort 2007-2008 